\title{
Industrialization Process of Pesticide Residue Grade n-Hexane
}

\author{
Can Quan ${ }^{1 *}$, Xiongwei Yan ${ }^{2}$, Ting Huang ${ }^{1}$, Hongmei $\mathrm{Li}^{1}$, Junsu $\mathrm{Jin}^{2}$ \\ ${ }^{1}$ National institute of metrology, 10013,Beijing, P.R.China \\ ${ }^{2}$ Beijing university of chemical technology ,10029,Beijing, P.R.China \\ Email: superfluidcan@hotmail.com
}

Received 2012

\begin{abstract}
This project is funded by the China government to develop the industrialization process of pesticide residue grade n-hexane, in which the industrial n-Hexane is used as crude purified by decoloration, distillation and filtration process. The products are validated by National Research Center for Environmental Analysis and Measurement (CNEAC), National Research Center for Geoanalysis, Chinese Academy of Inspection and Quarantine (CAIQ), Chinese Academy of Agricultural Sciences (CAAS) and other government originations for polychlorinated biphenyls, organochlorine pesticide or chiral pesticides analysis and further confirmed that it's competitive to all others imported n-Hexane currently occupied in China. This patented technique will meet pesticide residue grade n-Hexane market in China and seek for cooperation globally.
\end{abstract}

Keywords: Pesticide Residue Analysis Grade; $n$-Hexane; Purification; Distillation

\section{Introduction}

High purity organic solvents such as pesticide residue grade solvents play very crucial roles in scientific research field including chromatographic analysis, spectrum analysis, pesticide residue detection, mass spectrometry analysis, organic synthesis, combinatorial chemistry, DNA and RNA synthesis etc. In recent years, food safety problems have caused many concerns; pesticide residue content is one of the most important factors for food safety.

The objective of this study funded by Chinese government is to develop a commercial industrial process which can produce pesticide residue grade $n$-Hexane directly from industrial grade crude with capacity of $30 \mathrm{~T}$ annually.

\section{Experimental}

\subsection{Chemicals and Raw Materials}

Industrial grade $n$-Hexane crude was purchased from Beijing local market. High performance silicon dioxide decoloring agent with average particlon size of $100 \mu \mathrm{m}$ and specific surface area of $500 \mathrm{~m}^{2} / \mathrm{g}$ was purchased from Qingdao Fine Chemical Corporation (Shandong, China). All chemicals were used directly without further purification. The pesticide residue standards solutions were friendly contributed by the National Institute of Metrology (Beijing, China). Pesticide residue $n$-hexane control sample were kindly supported by Kingchemtune Co.Ltd.

\subsection{The Impurities of Industrial $\boldsymbol{n}$-Hexane}

The industrial $n$-Hexane is mainly separated from $6 \#$ solvent naphtha and raffinate oil which come from crude oil (Liang,T.X and M.Zhu,2004), however crude oil contains some aromatic and alkane compound, so industrial $n$-hexane may contain the said impurities. In order to verify the impurities of industrial $n$-Hexane which help to discuss the more availably purification process of pesticide residue grade $n$-Hexane, it is necessary to ascertain these specific impurities, in this situation, GC/MS analysis method is used to determine these impurities in qualitative model.

\subsection{Purification Proces}

- Distillation

The feedstock after decoloration was pumped for distillation, the 2-tower distillation apparatus were established with patented design. The industrial grade $n$-Hexane crude decolorated was firstly pumped into the $1^{\text {st }}$ distillation tower, in which those light impurities were separated, and the remains at the bottom were pumped again into the $2^{\text {nd }}$ distillation tower, in which those heavy impurities were switched at the bottom, the product can be collected on the top of the $2^{\text {nd }}$ tower, the product can be online monitored by a online GC/ECD.

\subsection{Analytical Method}

- UV Value analysis

For the analysis for the product of this process, UV value was measured via UNICO 2102-PCS ultraviolet spectrophotometer (USA) at the wavelengths from $195 \mathrm{~nm}$ to $250 \mathrm{~nm}$, with ultrapure water as blank in $1 \mathrm{~cm}$ cuvette.

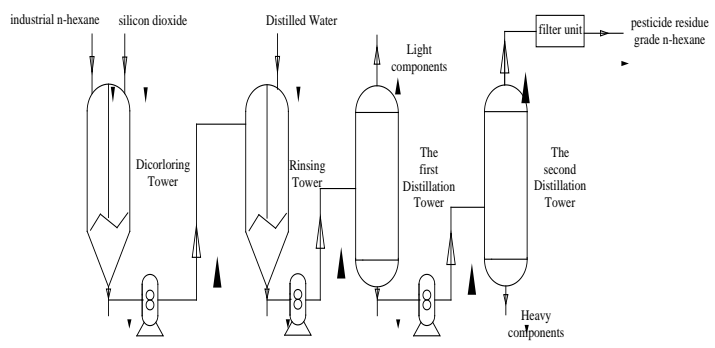

Figure 1. Purification process of pesticide residue grade $n$-Hexane. 
- Gas chromatography-electron capture detector (GC/ECD) analysis

For the analysis for the product by this process, GC/ECD analysis was carried out by Agilent 6890(USA) gas chromatography equipped with $\mathrm{Ni}^{63}$ electron-capture detector. Samples were introduced into the GC-column via electronic pressure control, with cold-column injector mode.

- Gas chromatography-mass spectrometry (GC/MS) analysis

For the analysis for industrial grade n-hexane and the product by this process, GCMS analysis was carried out by SHIMADZU GCMS-QP2010 Plus. Samples were introduced into the GCMS via electronic pressure control, with cold-column injector mode.

\section{Results and Discussion}

\subsection{Impurities Determination of Industrial $\boldsymbol{n}$-Hexane}

- Solvent peak

In GC/MS analysis, solvent peak should be found and cut. Industrial $n$-hexane contain many impurities, however, whose purity is still up to $96 \%$, after it is injected to GC/MS, the $n$-Hexane cannot be detected by MS, or the MS will be damaged by $n$-Hexane solvent, meanwhile it is hard to analysis those impurities peak because of ultra high main solvent peak.

In order to determine the retention time of solvent peak, the less injection volume and higher split ratio is chosen that is $0.1 \mu \mathrm{L}$ and 100:1 respectively, the result is showed in Figure 2.

\subsection{Parameters of Purification Process}

- Two towers distillation

After the processes of the front two steps, the feedstock was transferred to two distillation units, the use of the first tower was to remove the low point constituents, then the remaining liquid was transferred to the second tower, the use of which was to remove the high point constituents, lastly the product was got from the second tower top.

Distillation is a highly efficient separation method whose advantages are simple process, high effect and flexible operation etc. The controlled indexes of this process included heating temperature, reflux ratio and heavy constituents discharge rate etc. After a lot of experiments the optimized process parameters are got: the heating temperature of two towers distillation is $88^{\circ} \mathrm{C}$ with reflux ratio of $15: 1$ and $4: 1$ for both respectively, the discharge rate of heavy components is $20 \mathrm{~mL} / \mathrm{min}$, the yield is approximately $70 \%$. If heating temperature was too high and too low, they would cause flood and effect mass transfer, meanwhile if reflux ratio was too high, it would cost too much energy, else if the reflux ratio was too low, products were hard to meet the requirement, so it is necessary to find the best reflux ratio which is the essential elements of distillation operation.

\subsection{Quality Assessment of the Product}

- UV value measurement

Take $n$-Hexane crude and three bottles of different batches of products as the test sample with ultrapure water as blank, from Table 1, it can be seen that crude $n$-hexane cannot pass the UV value indexes, while UV value of all the products meet the UV value indexes at all the tested wavelengths.

The results show that the numbers of crude impurities are too many and the height is too high, three products show three time points which are most easy to appear exceeding peak respecttively.

The results showed that the purity of crude is less than $97 \%$ and the purity of these products reach $98 \%$ which meet the requirement of pesticide residue standard that is higher than $97 \%$.

\subsection{The Comparation of the Quality of our Product and Other Products Both at Domestic and Aboard}

From the test results, we can make the conclusion that the products got by this process meet the requirement of pesticide residue indexes. In order to analyze the market situation, we bought 5 kinds of brands of pesticide residue grade $n$-hexane both at domestic and abroad, all the products were tested in the said test method, the results were showed in Table 1.

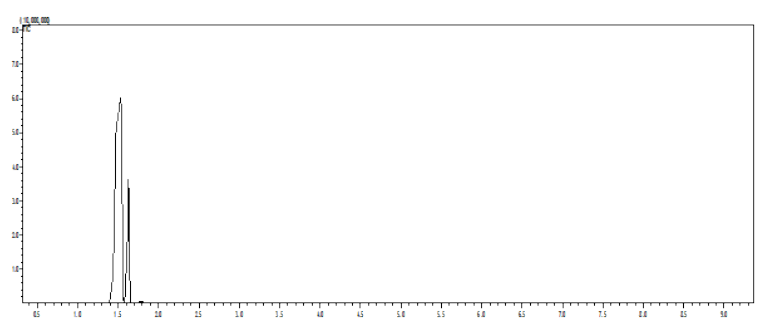

Figure 2. The main solvent peak.

Table 1. Quality comparison of pesticides residue $n$-Hexane.

\begin{tabular}{|c|c|c|c|c|c|c|}
\hline title & $\begin{array}{l}\text { Foreign } \\
\text { product } 1\end{array}$ & $\begin{array}{l}\text { Foreign } \\
\text { product } 2\end{array}$ & $\begin{array}{l}\text { Foreign } \\
\text { product } 3\end{array}$ & $\begin{array}{l}\text { Foreign } \\
\text { product } 4\end{array}$ & $\begin{array}{l}\text { Domestic } \\
\text { product } 1\end{array}$ & The product \\
\hline 195nm absorbance & 0.702 & 0.713 & 0.662 & 0.732 & 0.908 & 0.943 \\
\hline 220nm absorbance & 0.061 & 0.079 & 0.072 & 0.058 & 0.098 & 0.071 \\
\hline 230nm absorbance & 0.029 & 0.042 & 0.038 & 0.028 & 0.049 & 0.028 \\
\hline 240nm absorbance & 0.015 & 0.026 & 0.023 & 0.015 & 0.025 & 0.012 \\
\hline 250nm absorbance & 0.010 & 0.018 & 0.016 & 0.011 & 0.016 & 0.005 \\
\hline $\begin{array}{l}\text { Maximum peak height } \\
(\mathrm{GC}-\mathrm{ECD})\left(\mathrm{ng} \cdot \mathrm{ml}^{-1}\right)\end{array}$ & 2.83 & 0.26 & 0.18 & 6.31 & 1.38 & 0.590 \\
\hline purity (\%) (GC-FID) & 97.31 & 99.61 & 98.53 & 98.59 & 97.33 & 98.48 \\
\hline
\end{tabular}


The results show that the overall quality of the product got by this process ranks middle, which is better than domestic product and part of foreign products and have not big gap with other better foreign products.

In addition, the products were tested by National Research Center for Environmental Analysis and Measurement (CNEAC), National Research Center for Geoanalysis, Chinese Academy of Inspection and Quarantine (CAIQ), Chinese Academy of Agricultural Sciences (CAAS) and other government originations for polychlorinated biphenyls, organochlorine pesticide or chiral pesticides analysis and further confirmed that it's competitive to all others imported brand occupied China.

\section{Conclusion}

For the solvents of pesticide residue analysis, they not only require high purity, but more importantly, which do not produce interference peak in pesticide chromatographic detection when solution are concentrated dozens to hundreds times, so the traditional purification methods are not suitable for the preparation of this kind of solvents. This study build a new process, which can remove the trace impurities that influence the pesticide residue analysis and overcome some technology bottleneck problems such as complex process, too much impurities peak and heavy environment pollution, thus achieve the process of transforming industrial $n$-Hexane to pesticide residue grade $n$-hexane directly.

Put industrial $n$-hexane as crude, after this process containing decolour-two towers distillation-filter, pesticide residue grade $n$-Hexane which can be apply to pesticide residue analysis were prepared.

This product can meet the clients in the need of pesticide residue analysis, which would reduce the independent of domestic laboratory to imported pesticide residue grade solvents and could support the product of good quality and cheap price.

\section{Acknowledgements}

Can QUAN acknowledges the Ministry of science and technology of People's Republic of China for Key Projects in the National Science \& Technology Pillar Program during the Eleventh Five-Year Plan Period (2009BAK61B02); the Minis- try of science and technology of People's Republic of China (2011FY130100); the General Administration of Quality Supervision, Inspection and Quarantine of the People's Republic of China (ASPAQ1101-1); the National Institute of Metrology (21-JB1127) for financing.

\section{REFERENCES}

[1] Yang P, Ye X N, Lau C W. Design of efficient zeolite sensor materials for $n$-hexane [J]. Anal. Chem., 2007, 79(4): 1425-1432

[2] Sivasankar N, Vasudevan S. Adsorption of $n$-hexane in zeolite-5A: a temperature-programmed desorption and IR-spectroscopic study [J]. J. Phys. Chem. B, 2005,109(32): 15417-15421

[3] Bárcia P S, Silva J A C, Rodrigues A E. Adsorption equilibrium and kinetics of branched hexane isomers in pellets of BETA zeolite[J].Microporous and Mesoporous Materials, 2005, 79(1-3): 145-163

[4] Krishna R, Van baten J M. Screening of zeolite adsorbents for separation of hexane isomers: a molecular simulation study [J]. Separation and Purification Technology, 2007, 55(2): 246-255

[5] Yonli A H, Bouillault N, Mignard S. Separation of monobranched and dibranched isomers of $n$-hexane on zeolitic molecular sieves: a thermodynamic study [J]. J. Phys. Chem. B, 2010, 114(13): 4465-4470

[6] Bárcia P S, Zapata F, Silva J A C. Kinetic separation of hexane isomers by fixed-bed adsorption with a microporous metal-organic framework [J]. J. Phys. Chem. B, 2007, 111(22): 6101-6103

[7] Shanbhag P V, Guha A K, Sikar K K. Membrane-based ozonation organic compounds [J]. Ind. Eng. Chem. Res, 1998, 37(11): 4388-4398

[8] Bessarabov D G, Theron J P, Sanderson R D. Separation of 1-hexene/n-hexane mixtures using a hybrid membrane/extraction system[J]. Separation and Purification Technology, 1999, 16(2): 167-174

[9] Funke H H, Argo A M, Baertsch C D. Separation of close-boiling hydrocarbons with silicalite zeolite membranes[J]. J. Chem. SOC., Faraday Trans., 1996, 92(13): 2499-2502

[10] Gump C J, Noble R D, Falconer J L. Separation of hexane isomers through nonzeolite pores in ZSM-5 zeolite membranes [J]. Ind. Eng. Chem. Res.1999, 38(7): 2775-2781. 